\title{
Pillars of City Spatial Sensitivity and Their Integration into Sightseeing Routes
}

\author{
Melita Rozman Cafuta \\ University of Maribor, Faculty of Civil Engineering, Transportation Engineering and \\ Architecture, Slovenia \\ melita.rozman-cafuta@um.si
}

\section{Boštjan Brumen}

University of Maribor, Faculty of Tourism, Slovenia

bostjan.brumen@um.si

Worldwide, many cities have appropriate and necessary conditions for the development of urban tourism. Some locations, although considered important for local tourist destinations as part of a standard repertoire, do not comply with modern standards. For tourism organisations, it is very important to plan the best possible sightseeing routes with the best sightseeing locations. Using the intuitive approach only, is not enough in the modern tourism industry. The focus of the presented research is an innovative approach to identify the most prosperous urban places that should be included in urban tourist offers. Empirical research was conducted, based on the analytical method of mental mapping. For the research location, Maribor city (Slovenia, EU) has been chosen. A sample of 200 respondents was taken. They were asked to draw a city map twice, once for the daytime city and once for the nighttime city. Graphical results obtained reflect a subjective mental spatial idea of individual thinking mode. Some locations in the city seem to be particularly important and visible. They were named 'Pillars of Spatial Sensitivity' or, pss locations. Ps locations are extremely suitable to be integrated in a tourist offer as building blocks of sightseeing routes. When processing the research results, 34 Pss locations were more or less frequently detected in Maribor city. 32 of them had different appearance frequency between day and night. Based on these results, it is possible to conclude that modified spatial circumstances affect the perception and utilisation of urban space. The research results make it obvious that spatial sensitivity of tourists depends on time. It is possible to design sightseeing routes adapted to the time component.

Keywords: urban tourism, pillars of spatial sensitivity, mental map, sightseeing location

(cc)BY-SA https://doi.org/10.26493/2335-4194.13.157-166

\section{Introduction}

Urban tourism is 'a complex phenomenon, which is heavily involved in the local, regional and national environment' (Rangus et al., 2017, p. 167). Nowadays, it is rapidly expanding because people visit foreign cities for many different reasons as long-stay or short-stay tourists (Ashworth \& Page, 2011). Planning appropriate sightseeing routes has become a challenging task for tourist guides as well as for individuals visiting unfamiliar urban destinations. The whole city represents 
the physical place in which the tourist's desire is accomplished. Today, most cities aim to promote themselves as tourist destinations to increase their competitiveness, while tourism is seldom studied as an intrusive activity because of its indisputable positive economic effects (Fistola et al., 2019).

Visits to museums, galleries, and religious and archaeological sites are a usual part of the tourist's routine in urban destinations. Points of Interests should be narrowed down, and aligned with personal interests and trip constraints (Gavalas et al., 2016). However, field studies have revealed that tourists seek to maximize the time spent wandering around an urban space, engaging all their body senses while 'on the move' (Larsen, 2001; Shoval \& Isaacson, 2007). They appreciate observing everyday life activities and discovering different scenic values as much as they care about the cultural and architectural elements of a historical district.

Tourists today have become increasingly dependent on mobile city guides or tourist guide companies to locate tourist services and retrieve informative content (opening hours, entrance fees, etc.) about nearby points of interest. The main aim is planning the best possible sightseeing routes with the best sightseeing points. Ad hoc spatial decisions are no longer acceptable. The human dimension in the form of scenic route planning environmental perception sensitivity is not included.

Previous research on tour planning problems is broadly divided into several directions. Some studies are devoted to solving the mathematical programming problems. Other studies are devoted to dynamically planning an optimal itinerary which is related to designing intelligent tour planning systems (Hasuike et al., 2014). There is also research on various tour planning problems such as the tourist trip design problem (Souffriau et al., 2008), and the tour planning problem in a multimodal and time-scheduled urban public transport network (Zografos \& Androutsopoulos, 2008). However, existing mathematical models for sightseeing do not include subjective perception values of sightseeing places. Mental mapping is a useful method for revealing how visitors spatially perceive tourism destinations. However, studies of this kind are under-researched in the tourism field (Younghee Lee et al., 2018).

The focus of the presented research is to reveal urban places with a great perception value and to identify the most favourable areas that should be integrated into sightseeing routes. To ensure tourists' well-being and high environmental perception sensitivity are priorities. We assumed that, if some places trigger positive emotions for dwellers, they have the same positive impact on tourists. Although public preferences on environment are shaped by many different factors, such as age, gender, social and economic status, etc., there are also some common preferences on urban types, especially for people with similar educational background and environmental viewpoints.

Today's standard repertoire of sightseeing locations may not comply with modern standards. Therefore, it is essential to seek new locations to keep sightseeing routes attractive. Locations with high environmental perception sensitivity should be included. What is seen and what is remembered? After a while, tourists do not perceive every architectural and environmental detail. But they perceive well-being as a combination of environmental settings, people and service at the location. Tourists' spatial sensitivity changes over time. Do the appropriate sightseeing locations change too? In this context, the following is crucial: (a) to identify locations that have high spatial sensitivity and (b) to know when these locations can be integrated into sightseeing routes.

The research concentrates on a scientific approach based on an analytical method of mental mapping as an assessment tool. There is a tendency to answer all raised questions using the following hypothesis:

$\mathrm{H} 1$ Spatial sensitivity of tourists depends on time.

$\mathrm{H} 2$ Based on the value of spatial sensitivity, it is possible to design sightseeing routes adapted to the time component.

\section{Tourists' Cognitive Experience of the City and Spatial Sensitivity}

The structure of the city is not permanent. It changes over time. Urban development is guided by social progress and technological capabilities (Rozman Ca- 
futa \& Brumen, 2016). The city of tomorrow strikes a balance among social, environmental and economic needs (Rozman Cafuta, 2015). Urban tourism can contribute substantial economic benefits to certain city areas with a large and varied economic base. These gain the most from tourism but are the least dependent upon it (Ashworth \& Page, 2011). The challenge comes with lesser-known parts of the city with a low level of tourist infrastructure. How to seek for opportunities in such areas, especially if the economic base is weak? How to define potential places that are appropriate to be developed and integrated into sightseeing routes?

Generally, the environment should create a good personal feeling. To ensure satisfied tourists, environmental circumstances should be adjusted. To establish interaction between the urban environment and its users (tourists), it is necessary to understand how they perceive their surroundings. Spatial circumstances are not only material reality, but are also mental structures that result in subjective perception. Spatial sensitivity is always subjective because it relies on individual response. It is dependent upon the individual's gender, age, time, experience, and culture (Rozman Cafuta, 2015). Visual perception dominates over hearing, smell, taste, and touch. Eyesight provides the largest amount of information to explain what happens around us. We are supplied with a large amount of information such as: distance, colours, shapes, textures, and contrasts (Gregory, 1998).

Environment defines a cognitive image of a specific location, like any human performance that includes physical and mental links between an observed location and its surroundings (Canter, 1977). Using information obtained by different authors, a triangular scheme was created using a method of inductive conclusion in order to determine what influences tourists' spatial sensitivity (Figure 1). Tourists' spatial sensation depends on factors such as psychological, sociological, and aesthetic-functional. All of them are equal and connected. Tourists respond and act in accordance with them.

The scheme represents the most important factors and their indicators that must be taken into account when planning and arranging sightseeing routes, such as: sense of safety, orientation ability, path and loca-

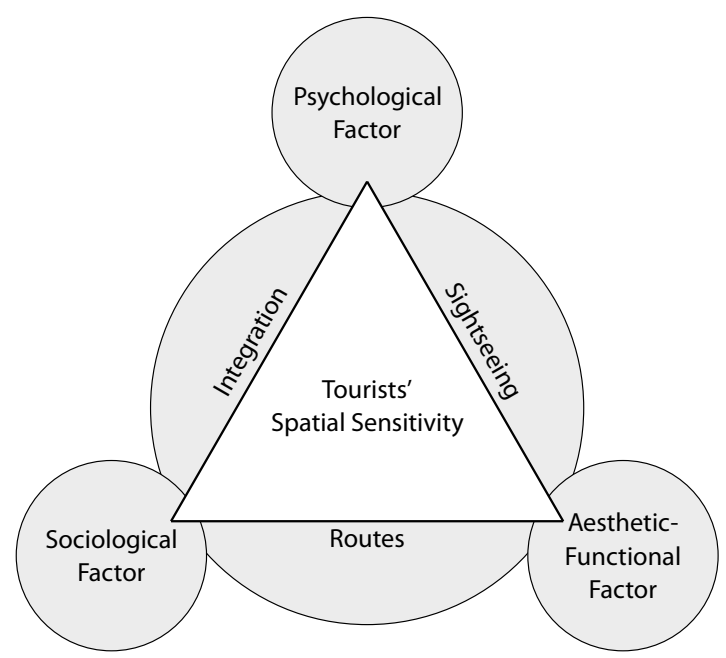

Figure 1 The Triangular Scheme of Tourists' Spatial Sensitivity Factors and Indicators

tion selection, way of movement, visual preferences and general place arrangement. The quality of service depends on it. Therefore, it is justified to explore how the time component and physical surroundings affect tourists' environmental sensation.

\section{Spatial Analysis by the Mental Mapping Method}

As already mentioned, environmental sensation is a complex process. Spatial sensitivity means recognising, collecting and organising received information. Through this procedure it is possible to be aware of our relative spatial position in relation to existing limitations. According to Canter (1977), the concept of space is based on individual cognitive experience and designated by the composite conceptual system. We are informed about a place through 'what behaviour is associated with, or is anticipated to be housed in it, what physical parameters of the settings are, and the description, or conceptions, which people hold of their behaviour in that physical environment' (p. 159). A place is set with a specific physical location and activities taking place in it. It is humans' cognitive experience of the material world and offers a concrete visual metaphor. The message of space ultimately depends on individual interpretation decomposing and recomposing its cryptic meanings (Šerman, 1997). 

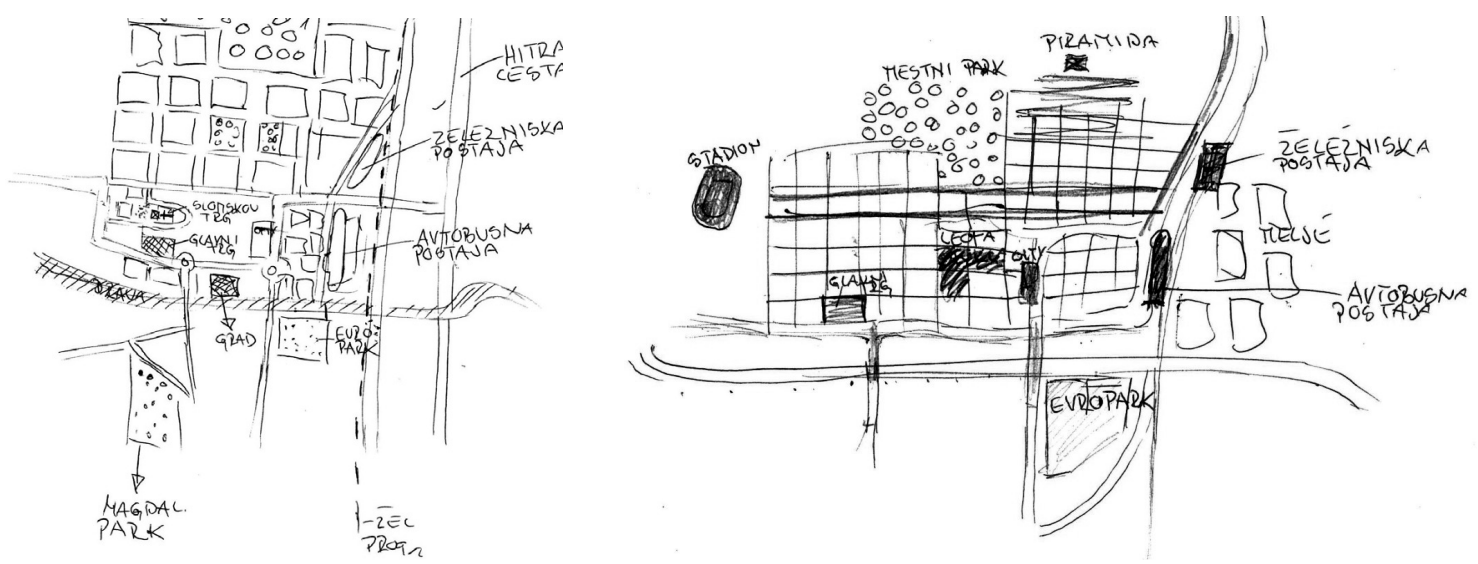

Figure 2 Mental Map of Maribor City (Slovenia, Europe); First During the Daytime and Second During the Nighttime (Graphical Output of Test Person)

In the sixties and seventies, urban theorists began studying the relationship between the reality and the idea of the space (Evans 1980; Liben et al., 1981; Lynch, 1960). Lynch's (1960) and Golledge's (1978) early studies have shown that our space perception can be articulated, evaluated and categorised. Tolman (1984) was the first who introduced the idea of cognitive mapping. Later, Downs and Stea (1973) upgraded his behavioural approach as a process composed of psychological transformations strings by which an individual acquires, codes, stores, recalls, and decodes information about the relative location and its attributes.

Today, cognitive mapping is the mental structuring process leading to the formation of a cognitive map. A cognitive map is a set of mental images. Environmental sensing enables identification of objects or areas, and determination of the distance between various points or patterns. Spatial visualization enables everyday movement, route planning, understanding the route descriptions and map reading. In more general terms, a cognitive map may be defined as an overall mental image or representation of the space and layout of a setting' (Arthur \& Passini, 1992).

Cognitive maps are a spatial representation of the outside world that is kept within the mind, until an actual manifestation (a drawing) of this perceived knowledge is generated, and a mental map is put down on paper. Cognitive mapping is the implicit, mental mapping the explicit, part of the process. Mental mapping has developed over the years. Today it has theoretical and practical potential to understand human environmental exchange. It comprises a subjective awareness of the surroundings and provides an insight into an individual's spatial sensitivity.

\section{Case Study: Maribor City}

In the presented research we upgraded the alreadyknown mental mapping method. In the previous practices, residents draw a map, from memory, of their city or some other research area. This allows the researcher to get a sense of which parts of the city are more substantial or imaginable. Tourists quickly developed cognitive images that are influenced by experience and the time spent in the area (Walmsley \& Jenkins, 1992). Similar use of mental maps is also applied in the presented research in order to identify specific points of interest that are sufficiently perceived and have enough potential to be included in sightseeing routes. Locations with high values of spatial sensitivity are generally the gathering sites of tourist spots. The research focus relied on a spatial impression of the city. It was attempted to give sensible form to the moods, feelings, and rhythms of functional life.

The conducted experiment was based on a sample of 200 respondents, 100 men and 100 women. All participants were students at the University of Maribor in Slovenia. The respondents can be equated as longterm tourists (they do not live at the research loca- 
Table 1 Occurrence Frequency of Pss Locations on Mental Maps

\begin{tabular}{|c|c|c|c|c|c|c|}
\hline \multirow[t]{2}{*}{ Pss location } & \multicolumn{2}{|c|}{ Day } & \multicolumn{2}{|c|}{ Night } & \multirow[t]{2}{*}{$\chi^{2}$} & \multirow[t]{2}{*}{$p$} \\
\hline & $f$ & $f \%$ & $f$ & $f \%$ & & \\
\hline River Drava & 160 & 80.0 & 147 & 73.5 & 33.269 & 0.000 \\
\hline Gosposka Street & 24 & 12.0 & 14 & 7.0 & 20.585 & 0.000 \\
\hline Poštna Street & 25 & 12.5 & 17 & 8.5 & 4.858 & 0.000 \\
\hline Koroška Street & 26 & 13.0 & 19 & 9.5 & 10.552 & 0.001 \\
\hline L. Štukelj Square & 41 & 20.5 & 52 & 26.0 & 24.281 & 0.000 \\
\hline Castle Square & 26 & 13.0 & 19 & 9.5 & 21.926 & 0.000 \\
\hline Main Square & 84 & 42.0 & 84 & 42.0 & 29.528 & 0.000 \\
\hline $\begin{array}{l}\text { A. M. Slomšek } \\
\text { Square }\end{array}$ & 85 & 42.5 & 73 & 36.5 & 35.223 & 0.000 \\
\hline Lent, Old City & 58 & 29.0 & 42 & 21.0 & 14.115 & 0.000 \\
\hline City Park & 58 & 29.0 & 17 & 8.5 & 15.607 & 0.000 \\
\hline $\begin{array}{l}\text { Ski slope Mari- } \\
\text { borsko Pohorje }\end{array}$ & 29 & 14.5 & 19 & 9.5 & 8.573 & 0.014 \\
\hline Hills & 54 & 27.0 & 35 & 17.5 & 27.674 & 0.000 \\
\hline Footbridge & 47 & 23.5 & 37 & 18.5 & 37.747 & 0.000 \\
\hline Old Bridge & 133 & 66.5 & 115 & 57.5 & 42.553 & 0.000 \\
\hline Main Bridge & 92 & 46.0 & 84 & 42.0 & 34.253 & 0.000 \\
\hline Koroška Bridge & 68 & 34.0 & 56 & 28.0 & 35.651 & 0.000 \\
\hline University & 70 & 35.0 & 52 & 26.0 & 32.241 & 0.000 \\
\hline Town Hall & 25 & 12.5 & 16 & 8.0 & 5.590 & 0.018 \\
\hline Main Post Office & 15 & 7.5 & 8 & 4.0 & 10.811 & 0.001 \\
\hline Town Market & 12 & 6.0 & 5 & 2.5 & 10.551 & 0.001 \\
\hline Football Stadium & 55 & 27.5 & 37 & 18.5 & 19.491 & 0.000 \\
\hline $\begin{array}{l}\text { Shopping Centre } \\
\text { Europark }\end{array}$ & 87 & 43.5 & 87 & 43.5 & $44 \cdot 380$ & 0.000 \\
\hline
\end{tabular}

Continued in the next column

tion, they come and go like visitors) or dwellers (while studying, they live at the research location). For the research location Maribor city has been chosen. Maribor is a vibrant, and the second largest, Slovenian city. It is a centre of the Styrian region and a semi-important tourist destination with medieval historical value.

The experiment was based on a memorised drawing of a city map and elements within it during different time sequences. Respondents were asked to imagine the city and put down a map of it. They were encouraged to create two drawings, once for the day-
Table 1 Continued from the previous column

\begin{tabular}{lrrrrrrrr}
\hline \multirow{2}{*}{ Pss location } & \multicolumn{2}{c}{ Day } & & \multicolumn{2}{l}{ Night } & \multirow{2}{*}{$\chi^{2}$} & $p$ \\
\cline { 2 - 3 } & $f$ & $f \%$ & & $f$ & $f \%$ & & \\
\hline Medical Faculty & 29 & 14.5 & 23 & 11.5 & 2.814 & 0.092 \\
Shopping Centre & 25 & 12.5 & 25 & 12.5 & 14.426 & 0.000 \\
City & & & & & & \\
Hall Stuk & 26 & 13.0 & 29 & 14.5 & 37.319 & 0.000 \\
Main Rail Station & 45 & 22.5 & 27 & 13.5 & 34.918 & 0.000 \\
Medical Centre & 51 & 25.5 & 34 & 17.0 & 49.742 & 0.000 \\
Movie Theatre & 50 & 25.0 & 54 & 27.0 & 28.446 & 0.000 \\
Kolosej & & & & & & \\
Student Hostel & 20 & 10.0 & 12 & 6.0 & 7.723 & 0.000 \\
Monument NOB & 21 & 10.0 & 8 & 4.0 & 6.464 & 0.011 \\
Plague Monument & 20 & 10.0 & 26 & 13.0 & 14.324 & 0.000 \\
Engineering Facul- & 50 & 25.0 & 22 & 11.0 & 15.322 & 0.000 \\
ties & & & & & & \\
Franciscan Church & 28 & 14.0 & 17 & 8.5 & 16.730 & 0.000 \\
Theatre & 25 & 12.5 & 26 & 13.0 & 9.120 & 0.003 \\
\hline
\end{tabular}

time city and once for the nighttime city. They had 10 minutes to complete each drawing (20 minutes altogether).

\section{Results and Discussions}

The obtained drawings were analysed according to the included or excluded elements. Spatial sensitivity is the respondents' mental image reflection. Already, every element that appears on a respondent's map is a spatial sensitivity carrier. When graphical outputs were analysed, 36 elements, more or less frequently detected, were exposed, such as: streets, squares, parks, morphological features, architectural attractions, and urban furniture. All exposed elements appear at least 10 times or more during daytime; the detected frequency is at least $5 \%$ or more (Table 1 ). The results show that the responders noticed most of the locations lying in the city centre, but only a few points in the wider surroundings. Such location distribution confirms the assumption that locations in the city centre are very noticeable and have a high value of spatial sensitivity. It is not surprising that most of the sightseeing routes already take place in the city centre. However, expanding the sightseeing routes on selected locations 
in the wider surroundings should also be considered.

In the second phase, obtained graphical data were statistically processed and analysed using the SPSS Windows computer program. Methods of descriptive statistics (frequency and numerical analysis, the arithmetic mean of the difference between the mean, and standard deviation) and inferential statistics ( $t$-test for dependent samples, and Pearson's correlation coefficient $r$ ) were used. The results in Table 1 show that almost all listed locations have different occurrence frequency. All exposed locations have specific characteristics that differentiate them from their surroundings. Their common qualities are good visibility, good accessibility, transportation network involvement, high usage frequency, high quality of spatial arrangement, higher property and rental values, etc. These are spatial qualities that are strictly necessary for tourist locations. In the presented research such locations are named Pillars of Spatial Sensitivity (pss locations). Pss locations have high spatial sensitivity value. They are spatial identity carriers and they stay in tourists' minds for a long time. Occurrence frequency is a criterion of importance.

During the day the most often noticed locations are the River Drava (160 times), Old Bridge (133 times), Main Bridge (92 times), A. M. Slomšek Square (92 times), Shopping Centre Europark (87 times), Main Square ( 84 times) and so on. During the night the most often noticed locations are the River Drava (147 times), Old Bridge (115 times), Shopping Centre Europark (87 times), Main Square (84 times), Main Bridge (84 times), and A. M. Slomšek Square (73 times). It can be concluded that some locations are in the group of the most often noticed ones in nearly everyone's mind, regardless of the time period. Such locations are suitable to be a part of sightseeing routes.

Locations are less noticeable at night except for the following locations: 7 (Leon Štukelj Square), 22 (Theatre), 30 (Hall Štuk), 31 (Main Bus station), 34 (Movie Theatre Kolosej), and 38 (Plague Monument). The results of the $\chi^{2}$-test confirm that spatial sensitivity depends on time. In the majority of cases we reach a statistically characteristic difference in the incidence of elements between day and night at the statistically significant level $p<0.05$. Hypothesis one is con- firmed. Spatial sensitivity of tourists depends on time.

If we want to plan the best possible sightseeing routes, it is necessary to identify the specific locations that make the observed city distinctive. Locations with a high noticed frequency should be part of a sightseeing route. Obviously, they trigger positive emotions. Locations with a low noticed frequency should be excluded. The emotions could be negative or simply not strong enough. Sometimes a location is suitable just for a specific time sequence. Generally, there are the following possible scenarios:

1. The location has high spatial sensitivity value. Noticed frequency is high regardless of time sequence. The location should be included in sightseeing routes.

2. The location has low spatial sensitivity value. Noticed frequency is low regardless of time sequence. The location should be excluded from sightseeing routes or it should undergo a complete architectural renovation of the location to be more functional.

3. The location has variable spatial sensitivity value. Noticed frequency is low or high depending on the time sequence. The location should be included in sightseeing routes only at a certain time.

By presenting possible scenarios hypothesis two is also confirmed. Based on the value of spatial sensitivity, it is possible to design sightseeing routes adapted to the time component. Application in practice is shown in three cases in Maribor City.

\section{Example 1: Location Gosposka Street}

(Variable Spatial Sensitivity Value)

Gosposka Street is one of the oldest streets, shaped in the 17 th century. Today it is a part of a wider pedestrian zone and well-known market street. Buildings' ground floors are occupied by shops or services, while upper floors are residential flats. The street is well accessible from various directions. At night, buildings' verticals are not visible. Illuminated shop windows are accentuated. General street brightness is uneven.

The location belongs to the standard repertoire of most existing sightseeing routes. It has high noticed 

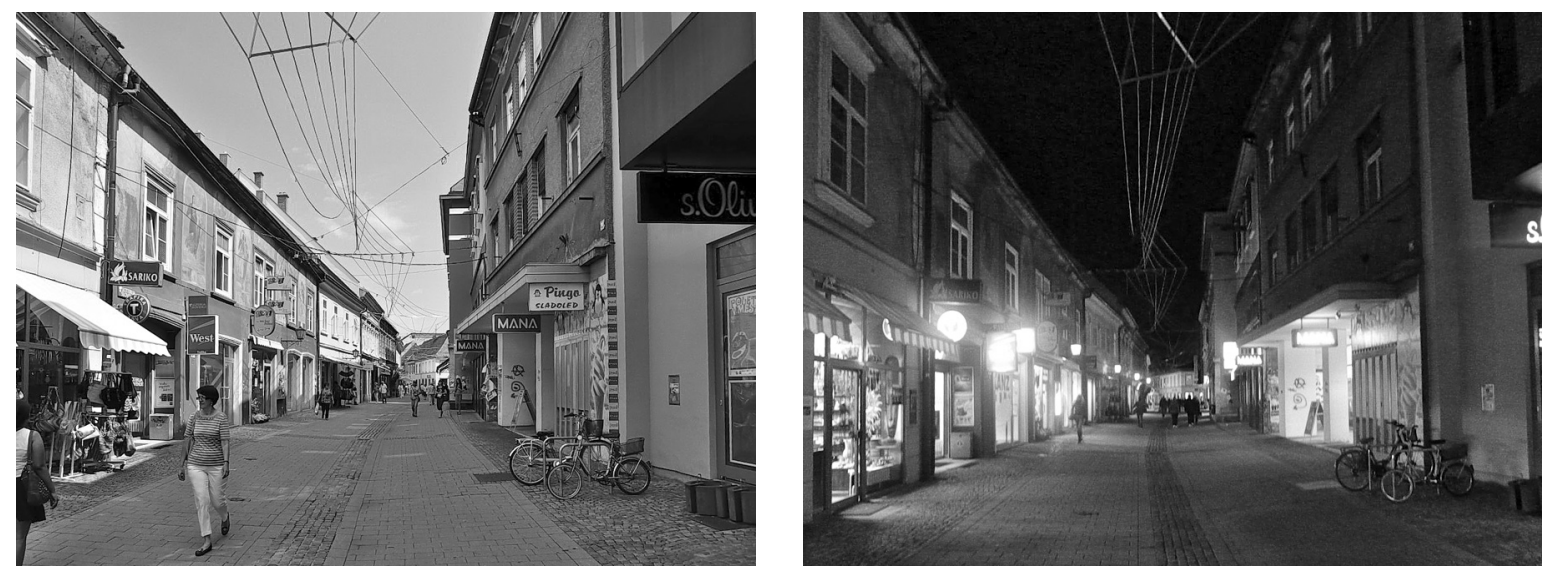

Figure 3 Gosposka Street During Daytime (left) and Gosposka Street During Nighttime (right)
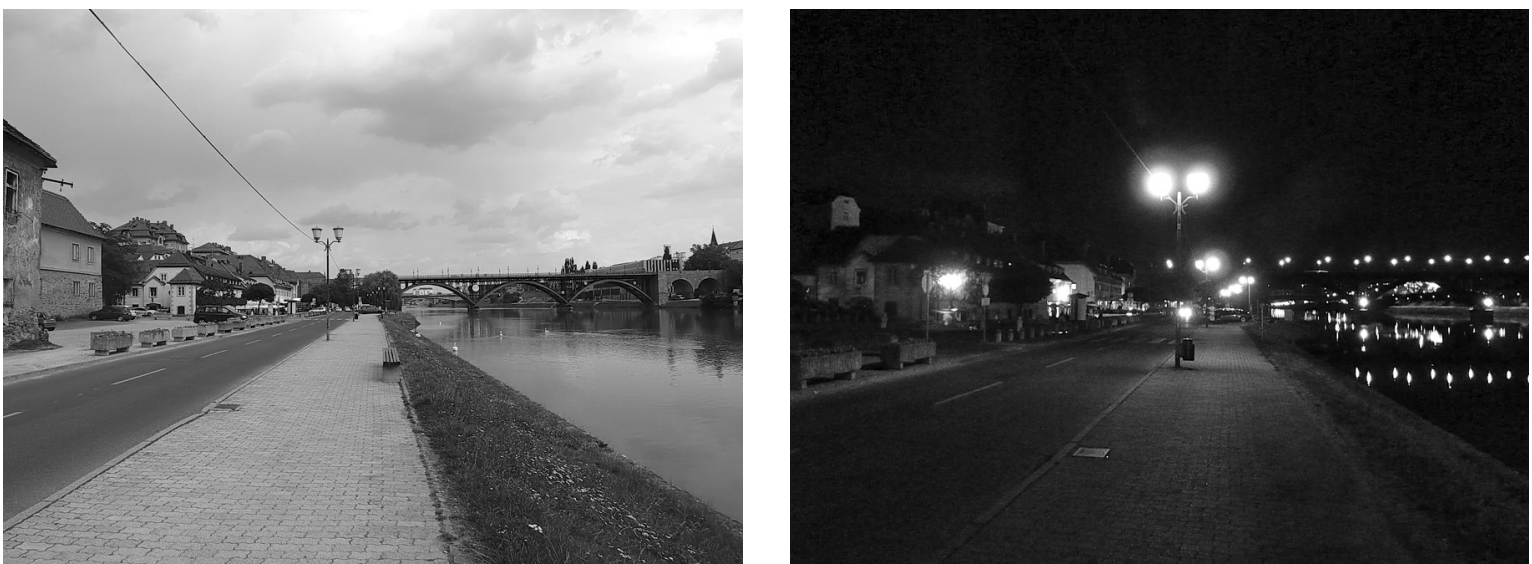

Figure 4 Old City Lent During Daytime (left) and Old City Lent During Nighttime (right)

frequency at daytime, so it seems to be very appropriate for daytime routes. But the location is not appropriate for organising nighttime sightseeing routes. Noticed frequency is low. Shops are closed and the environment seems not to be inviting enough.

\section{Example 2: Location Old City Lent}

(Low Spatial Sensitivity Value)

It is situated on the edge of the medieval city next to the river bank. The place is occupied by local streets and a sidewalk. Buildings are various typologies and ages. There are bars on ground floors and flats on upper floors. Illumination of the location is not sufficient; some parts are completely dark. The lights are placed on the sidewalk. The traffic area is minimally lighted. Lack of illumination at night makes walking freely more difficult. There are also several lights mounted on the buildings' walls. It is not sufficient because the open space remains in darkness.

The location belongs to the standard repertoire of most existing sightseeing routes. But the research results categorise the location as less attractive for inclusion in sightseeing routes because noticed frequency for day and night is low. The logical consequences would be to replace the location with another one. In this case such a recommendation is not the best 

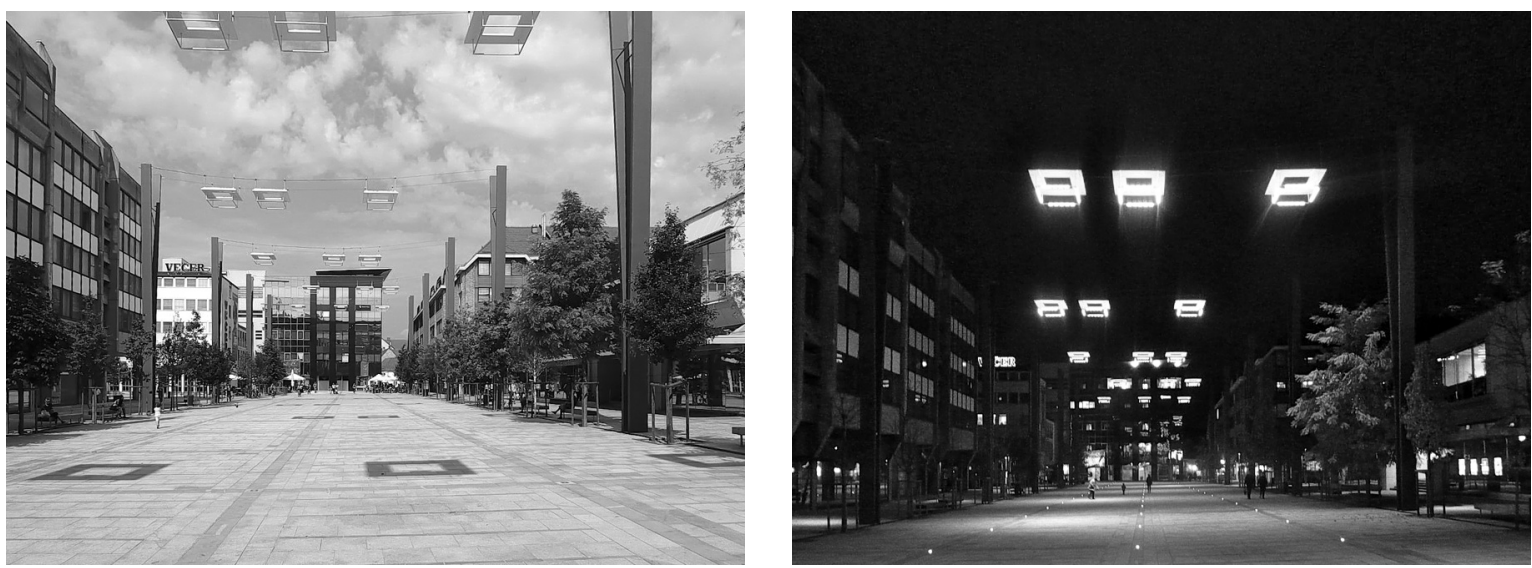

Figure 5 Leon Štukelj Square During Daytime (left) and Leon Štukelj Square During Nighttime (right)

option. The location has historical value and architectural renovation would be a better option.

\section{Example 3: Location Leon Štukelj Square (High Spatial Sensitivity Value)}

The square is situated in the city pedestrian zone. Redesigned, it was opened in 2011. The square is surrounded by public buildings. The central part of the square is devoted to public events and is therefore only occasionally occupied. Trees, benches, and bins are lined on both sides of the square. Hanging lamps are stretched across the area. Floor lamps are installed throughout the place. The square has a pleasant, unobtrusive illuminated atmosphere. At night, artificial light colour is changing and creates different ambiences. Hanging lamps illuminate the paved area. Facades are not illuminated.

The research results show high noticed frequency for both daytime and nighttime. Obviously, tourists noticed it and perceive a pleasant atmosphere during both time sequences. Based on the results, the location is very appropriate to be included in daytime as well as nighttime sightseeing routes. The tourist can sit, rest and enjoy the atmosphere.

\section{Conclusions}

Emerging tourism destinations can play a significant role in championing the adoption of sustainable tourism development (Sasidharan \& Križaj, 2018). Goeld- ner and Ritchie (2006) describe urban tourism as a complex phenomenon and extremely difficult to be described adequately. Any given location is primarily characterised by its natural environment, architecture and people. New opportunities must be sought in order to keep or to make all city areas attractive. Nowadays, tourists seek to maximize their environment with all the senses and appreciate observing everyday life. Social innovation needs to be constantly in place. This is even more important for occasionally visited places than for well-known tourists spots. Nowadays modern management companies and organisations must incorporate a psychological approach into their operations. It is a big challenge to satisfy tourists, because societal expectations are high. What do tourists remember and take home? What makes them come back and visit the same place again? Tourists certainly do not remember every architectural detail and historical fact. After a while, just a positive attitude and well-being remain. Sightseeing locations should be attractive, pleasant, safe, and should relax tourists at the same time. It is very important to plan the best possible sightseeing routes with the best sightseeing locations.

After analytical research work it is confirmed that modified spatial circumstances affect the perception and utilisation of urban space. Spatial sensitivity is subjective mental image reflection influenced by psychological, sociological and aesthetic-functional fac- 
tors. It provides an indication of a person's ability to perceive and remember visual information about a certain environment. It depends on time and changes as soon as spatial circumstances change, for example, day and night. Spatial sensitivity value is not always equal. The higher the value, the more important the location, the more it is suitable for integration into sightseeing routes. Summarising the graphical results obtained by the mental mapping method, it can be concluded that from the number of 34 exposed locations, 32 have different appearance frequency between day and night. Based on the value of spatial sensitivity, it is possible to design sightseeing routes adapted? to the time component. Some locations, although considered as important local tourist destinations, are not appropriate to be included in sightseeing routes. Only locations with high spatial sensitivity value in certain time sequences should become a part of sightseeing routes.

Obtained research results: (1) new definition of Pillars of Spatial Sensitivity (p s locations) set for the locations with high spatial sensitivity value, (2) the use of the already-known method of mental mapping for a new purpose (to identify pss locations and their spatial sensitivity value), and (3) hypothesis confirmation are original scientific contributions presented in this paper.

It is very important to plan the best possible sightseeing routes, but the proposed scientific approach cannot help the tourist organisation to make a location more attractive. Obtained research results provide insight into the spatial situation of Maribor city (Slovenia, Europe) and could support tourism development in a specific city area. The presented approach could be integrated as good practice in any other city worldwide. It supports identification of suitable sightseeing locations that are memorable and can be inherited by mobile city guides or used by tourist guides. Of course, other fields, such as tourist infrastructure and service quality, should also be considered.

\section{References}

Arthur, P., \& Passini, R. (1992). Wayfinding: People, signs, and architecture. Hill Ryerson.

Ashworth, G., \& Page, S. J. (2011). Urban tourism research:
Recent progress and current paradoxes. Tourism Management, 32(1), 1-15.

Canter, D. (1977). The psychology of place. Architectural Press.

Downs, R. M., \& Stea, D. (1973). Image and environment: Cognitive mapping and spatial behaviour. Aldine.

Evans, G. W. (1980). Environmental Cognition. Psychological Bulletin, 88(2), 259-287.

Fistola, R., Gargiulo, C., Battarra, R., \& La Rocca, L. A. (2019). Sustainability of urban functions: Dealing with tourism activity. Sustainability, 11(4), 1071.

Gavalas, D., Kasapakis, V., Konstantopoulos, C., Pantziou, G., \& Vathis, N. (2017). Scenic route planning for tourists. Pers Ubiquit Comput, 21, 137-155.

Goeldner, C. R., \& Ritchie, J. R. B. (2006). Tourism: Principles, practices, philosophies. Wiley.

Golledge, R. G. (1978). Learning about urban environments. In T. Carlstein, D. Parkes, \& N. Thrift (Eds.), Timing space and spacing time: Volume 1. Making sense of time (pp. 76-98). Edward Arnold.

Gregory, R. L. (1998). Eye and brain, the psychology of seeing. Oxford University Press.

Hasuike, T., Katagiri, H., Tsubaki, H., \& Tsuda, H. (2014). Sightseeing route planning responding various conditions with fuzzy random satisfactions dependent on tourist's tiredness. In S. I. Ao, O. Castillo, C. Douglas, D. D. Feng, \& J.-A. Lee (Eds.), Proceedings of the International Multiconference of Engineers and Computer Scientists 2014 (pp. 1232-1236). Newswood.

Larsen, J. (2001). Tourism mobilities and the travel glance: Experiences of being on the move. Scandinavian Journal of Hospitality and Tourism, 1(2), 80-98.

Liben, L. S., Patterson, A. H., \& Newcombe, N. (1981). Spatial representation and behavior across the life span. Academic Press.

Lynch, K. (1960). Image of the city. Institute of Technology.

Rangus, M., Brumen, B., \& Potočnik Topler, J. (2017). Sustainable tourism development in rural areas: The role of stakeholders. Academica Turistica, 10(2), 167-173.

Rozman Cafuta, M. (2015). Open space evaluation methodology and three dimensions evaluation model as a base for sustainable development tracking. Sustainability, 7 (10), 13690-13712.

Rozman Cafuta, M., \& Brumen, B. (2016). The innovative methodology of recognition the most appropriate places with a great potential for tourist satisfaction. In D. F. Kocaoglu, (Ed.), PICMET 2016: Technology management for social innovation (pp. 1824-1829). Portland International Center for Management of Engineering and Technology. 
Sasidharan, V., \& Križaj, D. (2018). Tourism ecolabels and social sustainability: Challenges and innovations from Slovene perspective. Academica Turistica, 11(1), 19-29.

Shoval, N., \& Isaacson, M. (2007). Tracking tourists in the digital age. Annals of Tourism Research, 34(1), 141-159.

Souffriau, W., Vansteenwegen, P., Vertommen, J., Berghe, G. V., \& Oudheusden, D. V. (2008). A personalized tourist trip design algorithm for mobile tourist guides. Applied Artificial Intelligence, 22(10), 964-985.

Šerman, K. (1997). O bîti i prostoru - Behrens i Loos*. Prostor: znanstveni časopis za arhitekturu i urbanizam, 5(2(14)), 201-238.
Tolman, E. C. (1984). Cognitive maps in rats and men. Psychological review, 55(4), 189-208.

Walmsley, D. J., \& Jenkins, J. M. (1992). Tourism cognitive mapping of unfamiliar environments. Annals of Tourism research, 19(2), 268-286.

Younghee Lee, M., Hitchcock, M., \& Wengsi, L. (2018). Mental mapping and heritage visitors' spatial perceptions. Journal of Heritage Tourism, 13 (4), 305-319.

Zografos, K. G., \& Androutsopoulos, K. N. (2008). Algorithms for itinerary planning in multimodal transportation networks. IEEE Transactions on Intelligent Transportation System, 9(1), 175-184. 